\title{
Okul Öncesi Dönemde Beden Algısı
}

\author{
DOI: 10.26466/opus. 829749
}

\author{
$*$
Mustafa Kale * - Sara Hurşidi ** - Ayşe Balcı Karaboğa ***
* Dr.Öğr.Üyesi., Çağ Üniversitesi, Mersin / Türkiye
ORCID: $\quad$ 0000-0002-1764-2224
** Öğretim Görevlisi., Çağ Üniversitesi, Mersin / Türkiye
ORCID: 0000-0002-8450-952X
*** Prof. Dr., Mersin Üniversitesi, Mersin / Türkiye \\ E-Posta: mustafakale@gmail.com \\ E-Posta: sarahursidi@gmail.com \\ E-Posta: aysebalci@gmail.com \\ ORCID: 0000-0003-3958-6582
}

\section{Öz}

Bu çalışmada, okul öncesi dönemde çocukların beden algısı üzerinde etkili faktörler, bu faktörlerin çocuklara etkileri ve okul öncesi dönemde beden algısının belirlenmesine ilişkin araştırma yöntem ve ölçme araçları hakkında literatür incelenmiş̧ir. Kişinin bedeni hakkında sahip olduğu olumlu ya da olumsuz değerlendirmelerin tümü, onun beden algısın oluşturur. Bireylerde beden algısının ve beden memnuniyetsizliğinin genellikle ergenlikte başladığı düşünülse de son yıllarda yapılan araştırmalar beden algısının okul öncesi dönemde başladığın işaret etmektedir. İlgili literatür incelendiğinde, okul öncesi çocuklarda bedene ilişkin memnuniyet ya da memnuniyetsizliğin aile, akranlar ve özellikle medya gibi faktörlerden etkilendiği görülmüştür. Erken yaşlarda beden memnuniyetsizliğine müdahale edilmediğ $i$ takdirde ise orta çocukluk ve ergenlik dönemlerinde düşük özgüven, sağlıksız beslenme alışkanlıkları ya da madde bağımlilı̆̆ı görülebilmektedir. Bu nedenle, okul öncesi dönemde çocukların beden algısının incelenmesi erken müdahale açısından büyük önem taşımaktadır. Ancak ülkemizde beden algısına ilişkin araştırmalar incelendiğinde, araştırmaları yoğun olarak ergenlik dönemine odaklandığ l, okul öncesi dönemde beden algısıyla ilgili araştırmaların oldukça sınırlı olduğu görülmüştür. Bu sınırlılı̆̆ın temel nedeni ise, ülkemizde okul öncesi dönem çocuklarının beden algısın değerlendirmeye yönelik ölçme araçlarının yetersizliğidir. Bu noktada mevcut çalışma, okul öncesi dönemde çocukların beden algısı ile ilgili literatürden örnekler sunması ve çocuklarda beden algısın incelemede kullanilabilecek araştırma yöntemleri ve ölçme araçların tanıtma noktasında önemli görülmektedir.

Anahtar Kelimeler: Beden algısı, erken çocukluk, beden memnuniyeti/memnuniyetsizliğ $i$ 


\title{
Body Image in Preschool Period
}

\begin{abstract}
In this study, the factors affecting the body image of children in the preschool period, the effects of these factors on children and the research methods and measurement tools related to the determination of body image in the preschool period are discussed. All of the positive or negative evaluations about a person's body constitute his body image. Although it is thought that body image and body dissatisfaction in individuals generally start in adolescence, studies conducted in recent years indicate that body image starts in the preschool period. When the relevant literature was examined, it was seen that satisfaction or dissatisfaction with body image in preschool children was affected by factors such as family, peers and especially the media. If body dissatisfaction is not intervened at early ages, low self-esteem, unhealthy eating habits or substance addiction can be seen in middle childhood and adolescence. Therefore, examining children's body image in preschool period is of great importance in terms of early intervention. However, in Turkey, it has been observed that the researches on body image focus heavily on adolescence, and the studies on body image in the preschool period are quite limited. The main reason for this limitation is the inadequacy of measurement tools to determine the body image of preschool children in Turkey. At this point, the present study is important in terms of presenting examples from the relevant literature on children's body image in preschool period and introducing research methods and measuring tools that can be used to examine body image in early childhood.
\end{abstract}

Keywords: Body image, early childhood, body satisfaction / dissatisfaction 


\section{Giriş}

Beden algısı kavramı ilk olarak Alman yazar Schilder tarafından 1935 'te İngilizce olarak yayınlanan “İnsan Vücudunun Görüntüsü ve Görünüşü” başlıklı çalışmasında önemli ve bütünleyici bir psikolojik fenomen olarak ele alınmıştır. Schilder çalışmasında, beden algısını, bireyin zihninde, kendi bedenine ilişkin oluşturduğu bir resim olarak tasvir etmiş ve kavramın her bireyin kendi bedenini nasıl gördüğüyle ilgili olduğunu ifade etmiştir. Daha sonra, 1958 'de Psikolog Seymour Fisher, psikanalitik bir perspektiften beden imajını incelemeye başlamış, beden algısı ile ilgili kitaplar ve bilimsel makaleler yayınlamıştır. Aynı dönemlerde, psikodinamik bakış açısını eleştiren Franklin Shontz, deneysel psikolojinin kuram ve verilerini çeşitli konularla bütünleştirmeye çalışmıştır. Shontz'un ele aldığ 1 konulardan biri de beden algısıdır. Beden algısını birçok faktör eşliğinde, çok boyutlu bir kavram olarak ele almış ve ilk olarak fiziksel engelli kişileri anlamak ve onlara yardımcı olmak için beden algısı çalışmalarını gerçekleştirmiştir (Cash, 2004). İzleyen süreçte, beden algısı üzerine hem temel hem de uygulamalı bilimsel araştırmaların artış gösterdiği, son yarım yüzyılda ve günümüze gelindiğinde ise araştırmaların etkileyici bir hızla devam ettiği görülmüştür (Neves, Cipriani, Meireles, Morgado, ve Ferreira, 2017). Bu araştırmalar, beden imajının psikolojik, sosyal, kültürel, biyolojik, tarihsel ve bireysel özellikler yanı sıra çeşitli faktörlerden güçlü bir şekilde etkilendiğini ortaya koymaktadır (Neves, Cipriani, Meireles, Morgado, ve Ferreira, 2017; Roosen ve Mills, 2014).

Beden algısı, kişinin bedeniyle ilgili düşünceleri, duyguları, algıları ve davranışlarını kapsayan geniş bir terimdir ve bu nedenle çok boyutlu bir kavram olarak kabul edilmektedir (Thompson, Heinberg, Altabe ve Tantleff Dunn, 1999). Beden alg1sı, bireyin bedeniyle olan pozitif ya da negatif bağlantısını, bedensel deneyimlerini, bedenine ilişkin duygularını, tutumlarını bütüncül olarak kapsar (Piran, 2016). Bu temelden yola çıkarak, beden algısı konusunda yapılan araştırmalar, insanların kendi bedeninin şekli, orantıları, büyüklügü ve görüntüsüyle ilgili algılarına, duygularına ve tutumlarına odaklanmaktadır. Bu odaklanmanın ana nedeni ise insanların bedenlerine ilişkin kaygılarının, onların fiziksel ve ruhsal açıdan sağlıklarına olan etkileridir. 
Beden algısı, algı ve tutum olmak üzere iki bileşen temelinde oluşmaktadır. Bu sınıflamada algısal bileşen, bireyin vücut büyüklüğüne ve şekline ilişkin tahminlerini, tutumsal bileşen ise bireyin kendi bedenine karşı sahip olduğu tutum ve duyguları ifade etmektedir. Algısal bileşen bir yargı olarak ele alınırken, tutumsal bileşen genel olarak duygu ve zihinsel temsillerle ilişkilendirilmektedir. Bu iki bileşen doğrultusunda birey bedenine ilişkin bir memnuniyet ya da memnuniyetsizliğe sahiptir. Beden algısı ile ilgili endişelerin, ergenlik döneminde vücudun değişime uğramasıyla birlikte başladığ yönünde genel bir kanı vardır (Cash, 2002b). Ancak farklı araştırmalar ilkokul çağındaki çocuklarda zayıf olma, ideal olma yargılarının bulunduğunu ve yedi yaşındaki çocukların bile bedenleriyle ilgili memnuniyetsizlik bildirdiğini ortaya koymaktadır (Dohnt ve Tiggemann, 2006; Levine ve Piran, 2004; Liechty, 2010). Hatta güncel araştırmalar, beden memnuniyetsizliğinin çok erken yaşlardan itibaren başlayarak yaşam boyu gelişim sürecinin diğer evrelerinde de bireyler üzerinde endişeye yol açtığı, fiziksel ve ruhsal sağlığı olumsuz etkilediğine ilişkin kanıtlar sunmaktadır (Birbeck ve Drummond, 2005; Cook, MacPherson ve Langille, 2007; Croll, 2005; Liechty, 2010). Beden memnuniyetsizliği yaş, cinsiyet, etnisite, vücut şekil ve ölçüsünden bağımsız herkesi etkileyebilmektedir (UK Parliamentary Report, 2012). Bu çalışma da, okul öncesi dönemde beden algısı, çocuklukta beden algısını etkileyen faktörler ve beden algısını değerlendirmeye ilişkin yöntemler ele alınmıştır.

\section{Beden Memnuniyetsizliği}

Beden alg1sı kavramsal olarak bedene ilişkin memnuniyet ya da memnuniyetsizlik üzerinden açıklanmaktadır. Kişinin vücudu hakkındaki olumlu düşünce ve duygulara sahip olması beden memnuniyeti olarak değerlendirilir. Ancak kişinin özellikle kilosu ve vücut şekline ilişkin olarak, hafif memnuniyetsizlikten yoğun nefret ve hatta bedenini reddetmesine kadar değişebilen olumsuz duygu ve düşüncelere sahip olması beden memnuniyetsizliği olarak ifade edilmektedir (Paxton ve McLean, 2010).

Beden memnuniyeti ya da memnuniyetsizliği tüm bedenin görünümüne yönelik olabildiği gibi, bazen vücudun belirli bir yönüne, belirli bir parçasına da yönelik olabilmektedir. Bedenin genel görünümü ya da bir parçasına ilişkin memnuniyetsizlik özellikle cinsiyete ve gelişim sürecine bağlı olarak değişkenlik gösterebilmektedir. Ergenlik döneminde kız çocuklarıyla yapılan 
bir çalışmada, ergenlik dönemi başlangıcında kız çocuklarının beden memnuniyetsizliğinin vücut ağırlığı ve şekline odaklanma eğiliminde olduğu belirtilmiştir. Bunun yanı sıra, aynı araştırmada ergen kız çocuklarının vücutlarının bölümlerine ilişkin memnuniyetsizliklerini yüz ve ciltlerine üzerinden bildirdikleri görülmüştür (Wertheim ve Paxton, 2011).

Ergenlik döneminin gelişimsel özellikleri, özellikle vücutta yaşanan fiziksel değişimler düşünüldügünnde beden memnuniyetsizliği anlaşılabilir bir durum olarak görülebilir. Ancak ergenler gibi okul öncesi dönemdeki çocukların da beden memnuniyetsizliklerini ortaya koyan araştırmalar mevcuttur. Örneğin, Drummond (2012), 5-8 yaş arası oğlan çocuklarıyla gerçekleştirdiği araştırmasında çocukların, kaslara sahip olma, uzun boylu, güçlü ve hızlı olma gibi ideal erkek vücuduna yönelik tanımlamalar yaptıklarını rapor etmiştir. Farklı bir çalışmada, oğlan çocukları beden memnuniyetsizliğini zayıf olma, yavaş olma ve kaslara sahip olmama olarak ifade etmişlerdir (Ricciardelli ve McCabe, 2001). Çocukların beden memnuniyetsizliği ve bununla birlikte ortaya çıkan endişeleri, gerçek fiziksel görünümden ziyade, algılanan görünüme odaklıdır. Kız çocukları kadın vücudunun ağırlığı ve biçimine, oğlan çocuklar ise erkek bedeninin güçlü ve kaslı olması şeklinde arzu ettikleri beden algısına sahiplerse ilerleyen gelişim evrelerinde bu bedene ulaşma çabası içine girebilmektedirler. Bu çaba çoğu zaman beslenme bozukluklarına, kaygı ve depresyona sebep olabilmektedir (Cash, 2002). Çünkü beden memnuniyetsizliği, sadece bir süreliğine mutsuzluk kaynağı olmaktan ziyade, ciddi olumsuz sonuçlara neden olabilmektedir.

\section{Kilo Önyargıları}

Beden algısına ilişkin tutumlar, çocukların sadece kendi bedenlerine yönelik değildir. Beden algısı ile ilgili tutumlar, çocuğun sosyal çevresinde yer alan aile üyelerine, akranlarına ve hatta tanımadığı diğer insanların görünümüne ilişkin olabilmektedir. Bu durum, uzun bir süre ten rengi ve ırksal özelliklerle temelinde ele alınmış, ancak son yıllarda küresel iletişimin genişlemesinin de katkısıyla vücutla ilgili klişeler, kilo ve şişmanlıkla güçlü bir şekilde ilişkilendirilmiştir. Kilo ile ilgili önyargılar, ilgili literatürde ağırlık ve vücut biçimine ilişkin önyargılar olarak ele alınmaktadır (Holub, Tan ve Patel, 2011; Neves, Cipriani, Meireles, Morgado, ve Ferreira, 2017; Puhl ve Suh, 2015; Spiel vd., 2016). 
Kilo önyargısı, tipik olarak, zayıf insanların zeki, arkadaş canlısı, başarılı ve iradeli olduğu inancı gibi, daha ince vücut ölçülerine sahip bireyler hakkında olumlu tutumları içerebilmektedir. Oysa daha şişman insanlar hakkında bu durum onlara yönelik olumsuz tutumlar gösterilmesine neden olur ve şişman insanların başarısız, tembel ve zayıf iradeli olabileceğine dair ön yargılarlar içerir (Damiano, Gregg, vd., 2015; Latner vd., 2007). Vücut biçimi ve kiloya ilişkin ön yargıların temelinde bir kişinin, beden algısının dışsallaştırılmış tutumları yer alır. Dışsallaştırma, bireyin kendi bedenine ilişkin duygu, algı, düşünce ya da inançlarını çevresine aktarmasıdır. Özellikle çocukluk döneminde dışsallaştırılmış beden algısına bağlı tutumların incelenmesi iki nedenden dolayı önemlidir. Birincisi, çocukların bu tutumlarının sürdürülmesi, onların daha büyük beden ölçülerine sahip bireylere karşı ayrımcllı yapmalarma neden olabilir ve ikincisi, bu tutumların uzun vadede olumsuz etkileri olabilir (Puhl ve Heuer, 2009).

Farklı araştırmalar, özellikle çocukluk döneminde, bedene yönelik ayrımcllığa maruz kalmanın çocuklar için birçok soruna neden olabildiğini ortaya koymaktadır. Örneğin, kilolu çocukların bedeni, çoğu zaman akranları tarafından alay konusu olabilir. Farklı araştırmalar, böyle bir durumda kalan çocukların, sosyal açıdan izole olma, zorbalığa maruz kalma, düşük benlik saygisı geliştirme, beden memnuniyetsizliği, düzensiz beslenme ve zihinsel sağlık sorunlarıyla karşılaşabildiklerini ortaya koymuştur (Eisenberg, NeumarkSztainer ve Story, 2003; Jendrzyca ve Warschburger, 2016; Latner ve Schwartz, 2005; Strauss ve Pollack, 2003). Bu açıdan değerlendirildiğinde, sadece kilosundan dolayı ayrımcılığa uğrayan çocuk için olumsuz bir durum yaşanıyor gibi görünmektedir. Oysa çocuklukta bedene ilişkin olumsuz tutuma sahip olma, sadece kilosundan dolayı ayrımcilığa uğrayan çocuklara değil aynı zamanda ayrımcılık yapan çocuklara da zarar vermektedir. Cooley, Elenbaas ve Killen (2016) önyargılar nedeniyle sosyal olarak dışlanan çocukların artan ruh sağlığı sorunları ve azalan akademik motivasyon nedeniyle riske girdiğini, ancak ayrımcılık yapan çocukların da farklılıklara sahip akranlarla sosyal etkileşime girmenin olumlu yönleri kaçırdıklarını öne sürmektedir.

Okul öncesi dönemden itibaren dişsallaştırılmış beden algısını incelemenin bir diğer önemli nedeniyse, bu süreçte sadece başkasının bedenine ilişkin olumsuz ve önyargi içeren tutumların, çocukların sonraki yaşamlarında etkili olmasıdır. Başkasının bedenine ilişkin oluşan olumsuz tutum ve ön yargılar 
yaşamın ilerleyen yıllarında, çocuk tarafından içselleştirilir ve kendi bedenini yargılamada bir ölçü olarak kullanılabilir (Paraskeva ve Diedrichs, 2020; Smolak 2011). Bu içselleştirme, çocuğun kendince "uygun kilo" algısı oluşturmasına, bu belirlediği uygun kilo ölçüleri dışında yer alan tüm ölçüleri olumsuz değerlerlendirmesine ve önyargılarının doğru olduğuna inanmasına yol açar (Damiano, Gregg ve diğerleri, 2015; Spiel ve diğerleri, 2016). Çocuklarla yapılan bu araştırmalarda, çocukların daha ince bedene sahip olmaya olumlu tutum gösterirken, kilolu olmaya ilişkin olumsuz tutum gösterdiklerini ortaya koymaktadır. Benzer şekilde, yapılan farklı araştırmalar, zayıf olma ve kilolu olmaya ilişkin önyargıların okul öncesi dönemde başladığını göstermektedir (Musher-Eizenman, Holub, Edwards-Leeper, Persson ve Goldstein, 2003).

Okul öncesi dönem çocuklarında çok dikkat çekici somut sonuçları gösteren çalışmalar sınırlı olsa da (Dittmar, Halliwell, ve Ive, 2006) ergenlik döneminde beden algısına ilişkin olumsuz tutumun patolojik sonuçlara yol açtı̆̆1 görülmektedir. Okul öncesi dönemde, gelişimsel bir müdahale açısından alınacak önlemlerin, ergenlik döneminde yaşanabilecek, psikolojik ve fiziksel problemleri önleyebileceği düşünülmektedir (Latner, Durso, ve Mond, 2013). Bu nedenle, okul öncesi dönemde beden algısının hangi faktörlerden etkilendiğinin belirlenmesi önem taşımaktadır.

\section{Çocukların Beden Algısını Etkileyen Faktörler}

Beden algısı, çocukluktan itibaren farklı faktörlerin etkisiyle inşa halinde olup, ön ergenlikle birlikte kilo kaygıları, bedenle ilgili inançlar ve fiziksel görünümü iyileştirmeye yönelik davranışlar olarak belirgin hale gelmektedir (Costa, Silva, Almeida, ve de Vasconcelos, 2015; Gleeson, ve Frith, 2006). Bilindiği üzere bebeklik döneminden itibaren çocuklar bedenlerinin farkında olmaya başlamakta ve kendi bedenlerini diğerlerinden ayırt edebilmektedir. Daha sonraki yıllarda, özellikle okul öncesi dönemle birlikte yakın sosyal çevre (aile üyeleri ve akranların beden algısından) ve medyanın da etkisiyle çocuklar kendi bedenlerini ve başkalarının bedenlerini değerlendirmeye yönelik yargilara sahip olmaktadırlar (Harrison ve Hefner, 2006; Tzampazi, Kyridis ve Christodoulou, 2013). Aşağıda çocukların beden algısı üzerinde etkili faktörlere ilişkin açıllamalara yer verilmiştir. 


\section{Ebeveynler}

Ailelerin tutum ve davranışlarının, okulöncesi çağdaki çocukların beden algisına nasıl ve ne derece etki ettiğini bulmak için birçok çalışma yapılmıştır. Ailelerin birden fazla şekilde çocuklarının beden algısına etki ettiği görülmüştür. Örneğin, Tremblay, Lovsin, Zecevic ve Lariviere (2011), okul öncesi çağda normal kilolu ve fazla kilolu çocukların beden imajını kavramsallaştırmaları, anlama yetenekleriyle, ebeveynlerinin çocukların bedenine ilişkin algıları arasındaki ilişkiyi incelemiştir. 3-5 yaş arası 104 çocukla (68 kız ve 76 erkek) beden algısı ve beden memnuniyetleri ile ilgili görüşmeler yapılmıştır. Çocuklarının beden algısına ilişkin ebeveyn algılarını değerlendirmek amacıyla bir anket uygulamışlardır. Araştırmada, özellikle, fazla kilolu çocukların ebeveynlerinin, çocuğun vücut ağırlı̆ğ ve büyüklügünü daha az olarak belirttikleri görülmüştür. Benzer şekilde, çocuklar da kendi vucut ölçülerini daha küçük ve hafif olarak ifade etmişlerdir. Araştırmacılar, çocukların yanlış değerlendirmelerini, gelişimsel sınırlılıklarının etkisi olarak değerlendirmişlerdir. Ancak ebeveynlerin, kilolu çocuklarını, daha zayıf olarak değerlendirmeleri, ebeveynlerin çocuklarının bedeni üzerinde belli bir beden alg1sina sahip olduğunu ortaya koymuştur. Tatangelo, McCabe, Mellor ve Mealey'nin (2016) yaptığı derlemede ise çocuğa bakım verenin beden memnuniyeti ile çocuğun beden memnuniyeti arasında bir ilişki olduğu görülmüştür. Ebeveynler anne ve baba olarak ayrı ayrı incelendiğinde ise annenin kilo kaygısının kız çocuklarındaki kilo kaygısı ile alakalı olduğu bulunmuştur. Kız çocuklarının kilosuyla ilgili kaygı yaşayan babalarla kız çocuklarının düşük benlik saygısı arasında da bir ilişki vardır. Aynı çalışmada, anne ve babaların kilo ile ilgili mesajlarında farklılaşma olduğu, annelerin kız çocuklarıyla iletişimlerinde kilo kaybına yönelik mesajların erkek çocuklarıyla iletişimde ise kas kütlesini arttırmaya yönelik mesajların fazla olduğu saptanmıştır. Kız çocuklarına kilo kaybı vurgulanırken oğlan çocuklarına kas kazanımı vurgulanması ilerleyen yaşlardaki beden memnuniyetsizliğinin sebepleriyle de paralellik göstermektedir. Hendy vd. (2001) anne mesajlarının çocukların vücut memnuniyetsizliği üzerindeki etkisini incelemiştir. 3 ila 6 yaşındaki kız ve oğlan çocukların annelerinden, çocuklarına ne sıklıkla daha kilolu veya daha zayıf sözlü mesajlar verdiklerini belirtmeleri istenmiştir. Sonuçlar, çocukları "daha kilolu" olmaya teşvik eden anne mesajlarının hem kız çocukların hem 
de oğlan çocukların beden algısını benzersiz bir şekilde etkilediğini göstermiştir. McCabe ve ark. (2007), 53 okul öncesi çağındaki çocuk ve anneleriyle yaptıkları araştırmada, görüşmeler yoluyla annelerin çocuklarına beden ölçüleriyle ilgili sözlü mesajlarının etkisi incelenmiştir. Annelerin kız çocuklarına daha fazla kilo verme mesajı ve oğullarına daha fazla kas kazanma mesajı ilettiklerini bulmuşlardır. Annelerin Oğlan çocukların kasları, kız çocukların ise kiloları ile daha çok ilgilendikleri bulunmuştur.

Wong ve ark. (2013) bakım verenlerin Tayvanlı okul öncesi çocukların beden imajı üzerindeki etkisini incelemiştir. Bu çalışma, bakım verenlerin, çocuklarının beden büyüklüğünden memnuniyetinin, çocuğun kendi beden ölçülerinden memnuniyetiyle ilişkili olduğunu göstermiştir. Cinsiyet farklılıkları bu çalışmada incelenmemiştir. Bu nedenle bu etkinin erkeklerde mi yoksa kadınlarda mı farklı olduğunu belirlemek mümkün değildir. Öte yandan, Striegel-Moore ve Kearney-Cooke (1993) tarafından yapılan araştırmada ebeveynlerin çok azının çocuklarının dış görünüşünü eleştirdikleri görülmüşsür. Ebeveynler genel olarak çocuklarını fiziksel olarak güzel bulmaktadırlar. Ebeveynler anne ve baba olarak ayrı ayrı incelendiğindeyse anlamlı bir farklılık bulunmamıştır. Yalnızca annelerin çocuklarının dış görünüşüyle ilgili müdahalelerde bulunmaya çalıştığı görülmüştür. Araştırmacılar bunun, annelerin geleneksel olarak dış görünüş de dâhil olmak üzere çocukların bakımından sorumlu tutulmalarından da kaynaklanabileceğini belirtmişlerdir. Çalışmanın bir diğer önemli noktası da ebeveynlerin tutumlarının, çocuklarının yaş aldıkça değişmesidir. Ebeveynler çocukları küçükken dış görünüşleri ile ilgili olumsuz bir tutumları yokken ergenliğe yaklaştıkça çocuklarının bedenleriyle ilgili daha eleştirel olmaya başlamışlardır. Kısacası, okulöncesi çocukların beden algısına ailelerin etkisi kilo ile ilgili algıların yanlışlı̆̆ı, kız ve oğlan çocuklarıyla iletişimlerindeki mesajların farklılığı ve çocukların yaş almasıyla beraber tutumların da değişmesi gibi birden fazla şekilde olabilmektedir (Damiano, Paxton, Wertheim, McLean, ve Gregg, 2015).

\section{Akranlar}

Çocukluk döneminde akran ilişkileri bireyin gelecek yaşamda kuracağı sosyal ilişkiler için önemli bir zemin oluşturur. Bu dönemde, çocukların akranları tarafından kabul ya da reddedilmesi, onların sonraki gelişim aşamala- 
rında kuracakları akran ilişkilerini sürdürmelerinde oldukça önemlidir. Özellikle okul öncesi dönemde, kilo, beden ölçüleri gibi bedene ilişkin özellikler akran ilişkilerinde kabul ve reddedilme süreçlerinde etkili faktörler olabilmektedir. Hatta bu dönemde, farklı bedensel özelliklere sahip olan çocuklar akranları tarafından reddedilebilmekte ve sıklıkla zorbalığa maruz kalabilmektedir (Cooley, Elenbaas ve Killen, 2016; McCabe ve Ricciardelli 2003; McNinch, 2013; Tiggemann 2006). Akranları tarafından görünüşüne bağlı olarak alay konusu olan çocuklar bu olumsuz geribildirimlerin etkisiyle olumsuz beden algısına sahip olabilirler. Aynı zamanda akranların alaycı geribildirimleri çocuklarda olumsuz benlik gelişimi ve kişilerarası ilişkilerin gelişimi için de uzun vadeli problemlere neden olabilmektedir (Davison ve Birch 2002; Eisenberg vd., 2006). Buna rağmen mevcut literatürde, çocukluk döneminde beden algısında akran etkisi oldukça sınırlı ele alınmıştır. Birbeck ve Drummond (2006b), okul öncesi çağında oğlan çocukların beden algısını inceledikleri çalışmalarında, oğlan çocukların akran tercihlerinde daha uzun ve ince olma, spor yapma gibi fiziksel görüntüyü öne çıkaran ifadelerde bulunduklarını tespit etmiştir. Akranlar beden algısı konusunda birbirleri üzerinde ayna etkisi de yaratabilmektedir. Benzer şekilde, Dohnt ve Tiggemann, (2006b), kı çocuklarında beden memnuniyeti ya da memnuniyetsizliğinde, akranlarının ideal bedene ilişkin yorumlarının ve medyada sunulan ideal beden algısının önemli rolü olduğunu bildirmişlerdir.

\section{Oyuncaklar, Ĕ̆itim Materyalleri ve Medya}

Çocukların beden algısında etkili diğer bir faktör, çocuklar için üretilen oyuncaklar ve hatta eğitim araçları olabilmektedir. Özellikle medya tarafından da desteklenen oyuncaklar, ideal beden algısını doğrudan ya da dolaylı bir biçimde çocuklara yükleyebilmektedir (Anschutz vd., 2009). Bu etkiler, ideal bir beden arayışında olan çocukların beden algısını kontrol altına alabilmekte olup, onlara sunulan ideal bedeni içselleştirmelerine neden olabilmektedir (Clark ve Tiggemann, 2008; Tatangelo, McCabe, Mellor, ve Mealey, 2016). Örneğin, ilk kez 1959 yılında üretilmeye başlamış olan Barbie bebekler günümüzde dünyada en yaygın kullanılan oyuncaklardan biridir. Barbie bebeklerin ilk üretimlerinden itibaren vücut ölçüleri, normal insanların asla sahip olamayacağı ölçülerdir (Brownell ve Napolitano, 1995; Sherman ve Zurbriggen, 2014). 
Her ne kadar günümüzde bu bebeklerin beden ölçüleri ile ilgili düzeltmelere gidilmiş olsa da insan bedeni ölçüleriyle orantılı bir görüntüye sahip değildir. Rice, Prichard, Tiggemann ve Slater (2016), 5-9 yaş kız çocuklarıyla gerçekleştirdikleri bir çalışmada Barbie bebeğe sahip kız çocuklarının da ince bedene sahip olmayı içselleştirmede etkili olduğu ancak, çocukların beden saygisı ve beden memnuniyetsizliği üzerinde bir etkisinin olmadığını rapor etmişlerdir. Ancak çocukluk döneminde beden algısının ve bedene ilişkin tutumun şekillendiği düşünüldüğünde, gerçekçi olmayan bir beden ölçüsünün ilerleyen yaşlarda risk faktörü olabileceği belirtilmektedir. Benzer şekilde çocuklara sunulan ideal bir beden ölçüsü onların diğer akranlarını da bu ölçüler üzerinden değerlendirmelerine neden olabilmektedir.

Beden algısını etkileyen bir diğer faktör ise medyadır. Yazı ve görsel medyada bedenin sunumuna ilişkin dolaylı bir norm vardır ve bu normlar ideal bedene vurgu yapmaktadır. Medya, ideal bedene ilişkin bu vurgusu, kadın ve erkek açısından farklılık göstermektedir. Kadınlar için sunulan ideal beden son derece ince iken erkekler için sunulan beden kaslı ya da fit olma kavramlarıyla betimlenmektedir (Hendriks, 2002). Örneğin, hem yazılı hem görsel medya ürünlerinde yer verilen görsellerde, beden algısı özellikle ince kadınlar, kaslı erkek mankenler ve aktrisler üzerinden iletilmektedir. Sinema, internet, televizyon ve dergi, gazete gibi görsel ve yazılı medya araçları aracllı̆̆ıyla temsil edilen bu iletiler, beden standartları belirlemede etkilidir (Hendriks ve Burgoon, 2003).

Çocuklarda beden algısına medya etkisini ele alan araştırmalar incelendiğinde ilgili literatürün oldukça sinırlı olduğu görülmektedir. Bu sınırlılık medyanın çocuk bedeni üzerinde etkilerini ortaya koymak için yeni çalışmaların yapılması gerektiğini de düşündürmektedir. Mevcut literatürde, Hayes ve Tantleff Dunn (2010), beden görünümü odaklı Disney filmlerine maruz kalmanın 3-6 yaş arası kız çocuklarının vücut memnuniyetsizliği üzerindeki etkisini incelemişlerdir. Bu çalışmada kız çocuklarına, bir dizi kısa animasyon Disney filmi izletilmiş ve daha sonra beden algılarına ilişkin etkiler incelenmiştir. Filmlerin, araştırmaya katılan kız çocuklarında kilo kaygısı üzerinde bir etkisi olmadığı belirlenmiştir. Ancak, çocukların beden algılarının, mevcut bedenlerinden daha ince olduğuna ilişkin alg1 ifadeleri tespit edilmiştir. Diğer bir çalışmada, Dittmar ve arkadaşları (2006), Barbie bebeklere maruz kalmanın, 5 yaşındaki kız çocukları arasında vücut memnuniyetsizliğinin artmasına neden olduğunu rapor etmişlerdir. Van Vonderen ve Kinnally 
(2012), medyanın beden algısı üzerindeki etkisiyle ilgili araştırmaların farklı sonuçlar vermesinin nedenini, beden algısının gelişim sürecinin birçok sosyal faktörle etkileşimli olmasından kaynakladığını belirtmişlerdir. Bu gerekçeyle, medyanın yanı sıra diğer sosyal ve kültürel faktörlerin de beden algısının gelişiminde önemli tamamlayıcı etkilerinin göz önüne alınarak değerlendirilmesini önermişlerdir.

\section{Okul Öncesi Dönemde Beden Algısının Belirlenmesi}

Beden memnuniyetsizliği ile ilgili araştırmalar, erken yaşlardan itibaren çocuklarda görülen beden memnuniyetsizliğine müdahale edilmemesi durumunda, özellikle ergenlik döneminde düşük benlik saygısı ve depresif belirtiler (Goldschmidt, Wall, Choo, Becker, ve Neumark-Sztainer, 2016), güvensiz cinsel davranışlar (Schooler, 2013), klinik yeme bozuklukları, fazla kilo, anoreksiya, sağlıksız diyet veya sağlıksız kas geliştirme davranışları (Pope, Kanayama, ve Hudson, 2012; Savaşhan Sarı, Aydoğa ve Erdal, 2015; Schebendach ve Roth, 2019), alkol ve sigara bağımlılığı olmak üzere olumsuz sonuçlar gösterdiğini ortaya koymaktadır.

Yakın zamana kadar, çocukluktaki beden memnuniyetsizliğinin uzun vadeli sonuçlarını araştıran araştırmalar oldukça sınırlıdır. Ancak, Davison, Markey ve Birch (2003) tarafından kız çocuklarıyla yapılan bir araştırmada, 5 - 7 yaş arasında kız çocuklarının yüksek kilo endişelerine bağlı diyet kısıtlamasına gitme ve sağlıksız yeme tutumlarının yer aldığını bildirmiştir. Bu bulgular ergenlerde yapılan diğer araştırma sonuçlarıyla tutarlıdır ve çocukluktaki vücut memnuniyetsizliğinin henüz yeterince tanımlanmamış olmamasına rağmen olumsuz sonuçları göz önüne alındığında bu konuda erken müdahaleler düşünülmelidir.

\section{Çocuklarda Beden Algısı Araştırmalarında Kullanılan Yöntem ve Araçlar}

Beden algısı ile ilgili çocukluk araştırmaları örneklem açısından değerlendirildiğinde, 6 yaş grubu çocuklardan başlayarak ergenliğe doğru bir yoğunlaşma olduğu görülmektedir. Bu durum daha önce de ifade edildiği üzere bedene ilişkin algının erken dönemde belirlenmesinin güçlüğünden kaynaklanıyor olabilir (Neves, Cipriani, Meireles, Morgado, ve Ferreira, 2017). Benzer şekilde, beden imajının ölçülmesinde de ölçülmek istenen boyuta göre beden ölçüsü/şekli, genel beden imajı, belirli beden kısımlarına ait beden imajı, 
dış görünüş, formda olma, sağlık, problemli yeme, figür üzerinden puanlama şeklinde farklılaşabilmektedir (Gragon, 2017; Paxton ve Damiano, 2017).

Ergenlik, yetişkinlik, ileri yetişkinlik gibi dönemlerde beden memnuniyeti ya da memnuniyetsizliğini belirlemek ve ne zaman başladığını tespit etmek oldukça kolay olabilmektedir. Ancak, bebeklik ve okul öncesi dönemde çocuklar için bu belirlemeleri yapmak oldukça zor olabilmektedir. Lewis ve Brooks-Gunn, (1979), bebeklerin yaklaşık olarak 9 aya kadar kendi görüntülerini başka bir bebeğin görüntüsünden ayırt edebildiğini, 2 yaşında ise bebeklerin kendi görüntülerini diğerlerinden görüntüler arasından seçebildiklerini belirlemişlerdir. Ancak çocukların kendi bedenlerini hangi dönemde ve nasıl değerlendirmeye başladıkları tam olarak belirlenmemiştir.

Smolak (2011), okul öncesi dönem çocuklarının bedene ilişkin değerlendirmelerden ziyade özellikle akran gruplarında daha çok sosyal bakımdan karşılaştırmalar yaptıklarını belirtmiştir. Çocukların akranları arasında yaptıkları sosyal karşılaştırmaların, daha sonra bedene ilişkin değerlendirmelerde etkili olduğunu ileri sürmüştür.

Bebeklik ve okul öncesi dönemi çocuklarla araştırma yapmak çocukların gelişimsel özelliklerine bağlı olarak sınırlılıklar getirebilmektedir. Bu durum çocuklarda beden algısı ölçümünde de karşılaşılan sınırlılıklardan biridir. Özellikle, çocuklarda beden algısının boylamsal olarak incelenmesi, ölçmenin farklı zamanlarda farklı ölçme araçlarıyla gerçekleştirilmesine bağlı olarak sağlıklı bir değerlendirme için oldukça zor olabilmektedir (Paxton ve Damiano, 2017).

Neves, Cipriani, Meireles, Morgado, ve Ferreira, (2017), okul öncesi dönemde beden algısını ele alan araştırmalarda konunun nitel, nicel ve karma yöntemlerle ele alındığını rapor etmişlerdir. Fakat bu araştırmalarda nicel yöntem kullanımının oldukça yoğun olduğu bildirilmiştir. Nitel araştırmalar ise oldukça sınırlı olup, veri toplama aracı olarak çoğunlukla görüşme tekniği tercih edilmiştir. Nicel ve karma araştırmalarda kullanılan ölçme araçları incelendiğinde ise üç başlıkta sınıflandığı görülmektedir. Bunlar, resimli değerlendirme ölçekleri (Collins, 1991; Truby ve Paxton, 2002), tutum ölçekleri (Brown, Cash ve Mikulka, 1990), video projeksiyon ölçekleri ve anketler şeklindedir. Ancak çocuklarda beden algısı ile ilgili araştırmalarda yoğunluklu olarak resimli değerlendirme ölçeklerinin kullanıldığı görülmektedir. 
Bu ölçeklerin arasında, en yaygın olarak kullanılan beden algısı değerlendirme ölçeği siluet testleridir. Siluet testleri, beden memnuniyeti veya memnuniyetsizliğini belirlemede, çocuklara farklı insan vücudu siluetlerinin yer aldığı aynı kâğıda basılı benzer görsellerle uygulanmaktadır (Gragon, 2017). Bu görsellerde çocuklara çok zayıf insan bedeninden başlayarak, çok büyük bedenlere kadar değişen siluetler, yaş ve cinsiyete uygun şekilde gösterilmektedir.

Görsellerde siluetler iki satırda ayrı ayrı sunulmaktadır ve her satırda zayıftan büyük bedene doğru sırayla yer alan siluetlerde 1'den başlayarak 7'ye kadar devam eden derecelendirme mevcuttur. Mevcut ölçekte, 1.ve 2. resim çok ince, 3. resim ince, 4. resim ortalama, 5. resim büyük, 6 ve 7. resimler ise çok büyük beden olarak kategorileştirilmiştir (Neves, Cipriani, Meireles, Morgado, ve Ferreira, 2017).

Görselde ilk satırda yer alan siluetler çocuklara gösterilmekte ve çocuktan bu siluetlerden hangisinin kendi bedenine benzediği sorulmakta ve seçtiği siluet puanı not edilmektedir. Ardından ikinci satırda yer alan siluetler gösterilerek idealinde yer alan beden belirlenmeye çalışılmaktadır. Araştırmacı, çocuğa "hangi bedenin sana ait olmasını isterdin?" sorusunu yönelterek sahip olmak istediği bedeni göstermesini ister ve çocuğun belirlediği siluetin puanını not eder.

Beden algısı, mevcut ve arzulanan beden puanlaması arasındaki farkın alınmasıyla belirlenir. Her ne kadar bu yöntem çocuklara beden memnuniyetsizliğinin değerlendirilmesi için yaygın olarak kullanılmış olsa da, ölçek farklı araştırmacılar tarafından, görsellerde yer alan siluet sayısı, görsellerin renkli ve renksiz kullanımı açısından farklılık göstermiştir. Özellikle bazı araştırmacılar, küçük çocuklar için ölçekte yer alan görevi daha anlaşılır kılmak için görselleri değiştirmiş ya da görsellerde yer alan insan silueti sayısını azaltmıştır (Gragon, 2017). 

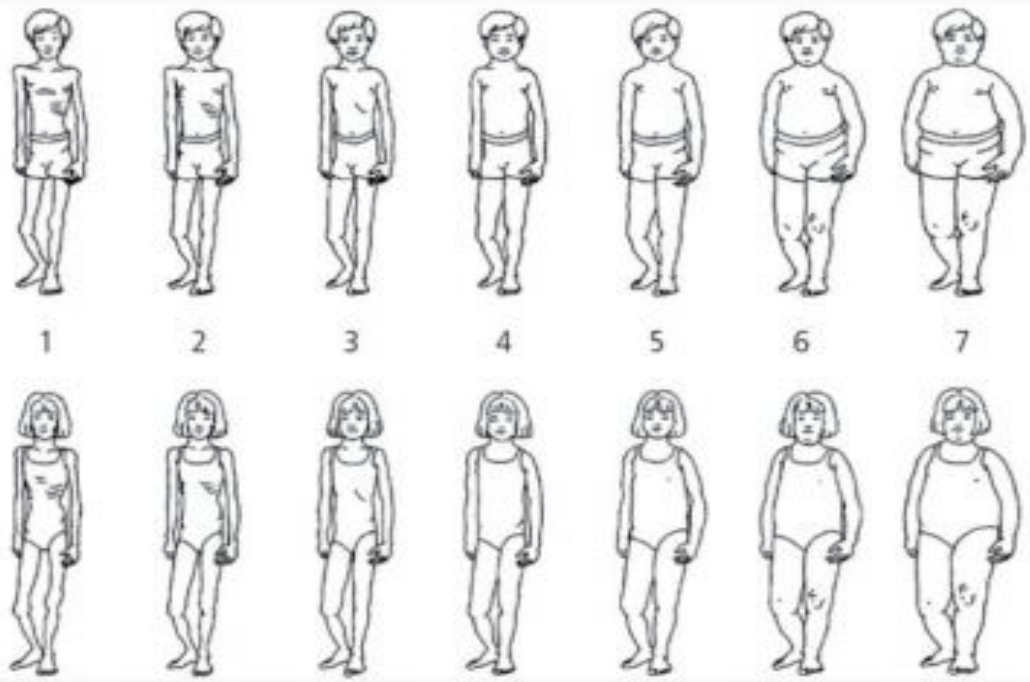

7

Şekil.1. Cinsiyete göre çocuklar için resimli beden algısı ölçeği (Collins, 1991).

Örneğin, çocuk beden algısı ölçeği (Children Body Image Scale), 7-12 yaş grubundaki çocuklarla yapılan görüşmelerde kullanılan bilgisayar ortamında hazırlanarak değiştirilmiş fotoğraflardan oluşan 7 basamaklı bir ölçektir (Truby ve Paxton, 2002). Yine, Lowes ve Tiggemann (2003), çocuk figürü derecelendirme ölçeği, 5-8 yaş arası küçük çocuklarda kullanılmış, 9 figürlü siluet çizimlerinden oluşan diğer bir ölçektir. Farklı bir araştırmada ise Musher-Eizenman vd. (2003), başlangıça Collins (1991) tarafından beden algıs1nın değerlendirilmesi amaciyla geliştirilen ölçeği, 4-6 yaşındaki çocuklar için yeni bir versiyon olarak 7 rakamlı bir siluet çizimleri ölçeğini kullanmışlardır.

Spiel, Paxton ve Yager (2012), 3 ve 5 yaşındaki çocuklarda ağırlık önyarg1larını değerlendirmek için, Tiggemann ve Pennington'ın, 1990 yılında hazırladıkları ölçeği revize etmişlerdir. Revize edilen yeni ölçekte, farklı vücut boyutlarını tasvir etmek için 2 boyutlu (2D) keçeden yapılmış mayolu bebekler kullanmışlardır. Ayrıca, araştırmacılar ölçeği uyguladıkları çocukların figürleri kendilerine yakın hissetmeleri ve seçim fırsatı verme amacıyla figürlerin saçlarını sarı ve siyah olarak renklendirmişlerdir (Şekil.2). Daha yakın zamanda ise, Damiano ve arkadaşları (2015), Spiel, Paxton ve Yager (2012) tarafından uyarlanan keçe oyuncak bebek siluet testinin 5 figürlü versiyonu dört yaşından küçük çocuklarda beden imajını değerlendirmek için kullanılmıştır. 

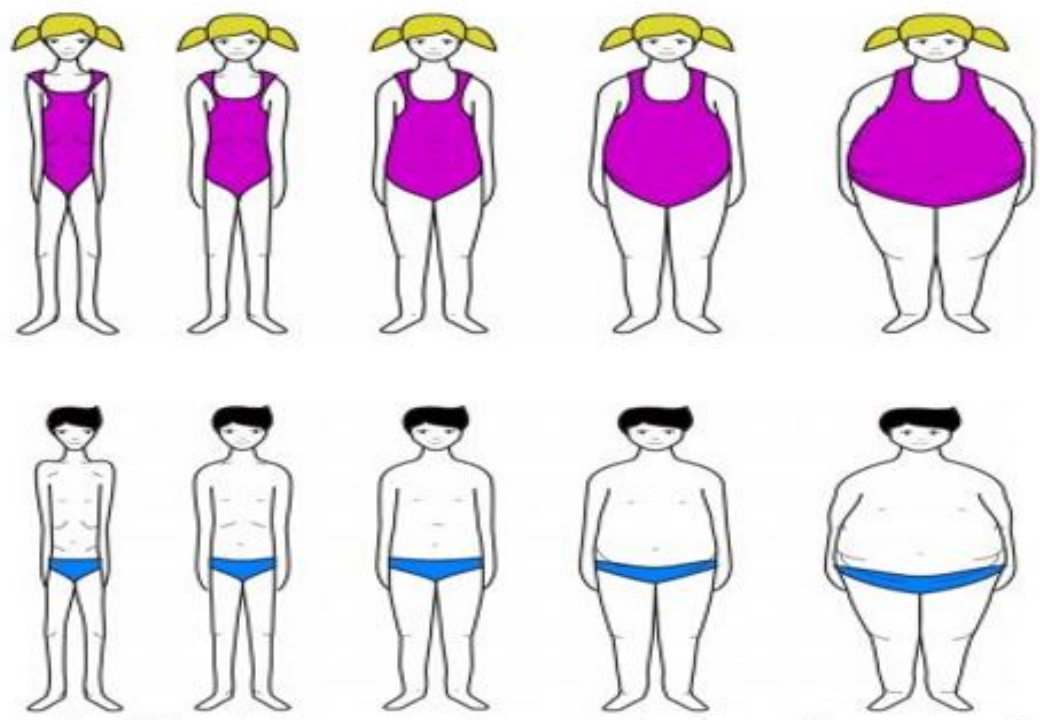

Şekil.2. Çocuk Beden Algısı Ölçeğinin Revize Edilmiş Görseli (Gragon, 2017).

Beden algısının diğer yaygın olarak kullanılan ölçüm araçlarından biri de anket ölçümleridir. Çocuklar için en sık kullanılan anketler, Beden Saygısı Ölçeği (Body Esteem Scale) (Mendelson ve White, 1982) ve Beden Memnuniyeti Ölçeğidir (Body Satisfaction Scale) (Slade, Dewey, Newton, Brodie ve Kiemle, 1990). Beden Saygısı Ölçeğinde, vücutlarından veya görünümlerinin bazı yönlerinden memnuniyetleri hakkındaki 24 ifade (örneğin, görünüşümden oldukça meтnипum) yer almaktadır. Çocuklardan bu ifadelere, evet veya hayır şeklinde yanıt vermeleri istenmektedir. Verilen yanıtlar değerlendirildiğinde, yüksek puanlar daha yüksek vücut saygısını göstermektedir. Beden Saygısı Ölçeğinin, 4-6 yaş arası çocuklardan oluşan daha küçük yaş grupları için iç tutarlılığa ve 7-12 yaş arası çocuklarda yarıya bölme yöntemiyle belirlenen güvenilirliğe ve eşzamanlı geçerliliğe sahip olduğu görülmüştür (Mendelson ve White, 1982). Beden Memnuniyeti Ölçeği ise kişinin vücudunun boy, kilo, vücut şekli, karın bölgesi ve yüz vb. 16 vücut parçasına ilişkin memnuniyetini değerlendirmesi için tasarlanmış 7'li Likert bir ölçektir (Slade ve ark., 1990). Ölçeğin farklı varyasyonları, farklı yaş gruplarından çocukların beden algısı önleme programlarında kullanılmıştır (Neumark-Sztainer, Sherwood, Coller 
ve Hannan, 2000; Sundgot-Borgen vd., 2020). Bu çalışmalarda, ölçek iç tutarlılı̆̆ın sağlandığı görülmüştür. Bununla birlikte, çocukların gelişimsel açıdan bedenlerine ilişkin tutumlarının hala şekillenmekte olduğu düşünüldügünde, ölçekler hakkında bazı eleştiriler de yapılmaktadır. Örneğin, küçük çocukların verdiği cevaplarda daha büyük olmak istemelerinin vücut memnuniyetsizliğinden mi yoksa çocuklarda sıklıkla karşılaşılan büyük olma, güçlü olma arzusundan mı kaynaklandığı çok net değildir. Bu açıdan değerlendirildiğinde, çocukların bu ölçekten aldığı puanların gerçek anlamını daha iyi tespit etmek için boylamsal çalışmalar yapılması önerilmektedir (Paxton ve Damiano, 2017).

\section{Türkiye'de Beden Algısı Çalışmaları}

Ülkemizde ise beden algısı ile ilgili ulaşılan ilk çalışmaların, Özbaydar (1967)' tarafından psikoloji alanında yazılan, "Vücut İmajı-İcedönüklük ve Dışadönüklük" adlı kitabıyla başladığı görülmektedir. Daha sonra, ülkemizde beden algisı ile ilgili tezler incelendiğinde 1996 yılında ilk lisansüstü tezin hazırlandığ belirlenmiştir. 1996 ile 2020 yılları arasında "beden algısı" ile ilgili farklı disiplinlerden 148 tez üretildiği görülmektedir. Ancak süreç incelendiğinde, beden algısı konusunda ülkemizde sınırlı sayıda çalışma yapıldığı ve bu çalışmaların özellikle 2016-2020 yılları arasında yoğunluk kazandığı görülmektedir (Yükseköğretim Kurumu Başkanlı̆̆1 Tez Merkezi, 2020).

Mevcut çalışmaların, örneklem açısından ön ergenlik, ergenlik dönemi ve yetişkinlik dönemlerine odaklanıldığ görülmektedir. Öte yandan, bebeklik dönemi ve okul öncesi dönemini ele alan araştırmalar oldukça sınırlıdır. Bu sınırlılık, beden algısı ile ölçme araçlarının ülkemiz de henüz uyarlama çalışmalarının yapılmamış olmasından kaynaklandığı düşünülebilir. Oysa uluslararası literatür incelendiğinde, çocukluk döneminde beden algısının incelendiği araştırmalarda nitel, nicel ve karma yöntemler kullanılmaktadır. Bunun yanı sıra, çocukluk dönemi beden algısı araştırmalarında yoğun olarak kullanılan görsel ölçeklerin farklı kültürlere uyarmalar yapılarak kullanıldığı görülmektedir.

Ülkemizde yapılan araştırmalarda, beden algısının yoğun olarak cinsiyet, yaş gibi demografik değişkenlerin yanı sıra ve hastalık, kaygı, benlik algısı, atılganlık düzeyi, diyet ve egzersiz gibi faktörlerle karşılaştırıldığı görülmektedir (Ata, Vural, Keskin; 2014; Koç ve Korkut Owen, 2019; Kurban, 2019). 
Mevcut araştırmaların, örneklemlerinde yoğun olarak kadınlarla çalışıldığı, erkeklerde beden algısı ile ilgili çalışmaların çok sınırlı olduğu görülmektedir. $\mathrm{Bu}$ araştırmalar, pozitivist bir yaklaşımla psikoloji, psikiyatri, tıp, beslenme ve diyetisyenlik, hemşirelik gibi sağlik alt alanlarında incelenmiştir (Haspolat, 2019; Helvalı, 2019; İncedal, 2016).

Sonuç olarak, beden algısının gelişimi birçok faktörün etkisinde gerçekleştiği düşünüldüğünde (Gragon, 2017), ülkemizde farklı disiplinlerde ve hatta farklı disiplinlerin birlikte beden algısını incelediği araştırmalara ihtiyaç duyulmaktadır. Benzer şekilde, ülkemizde özellikle bebeklik ve okul öncesi dönem çocukların beden algısına yönelik ölçek geliştirme ve uyarlama çalışmalarına ihtiyaç duyulmaktadır. Bu bağlamda, kültüre duyarlı ölçme araçlarının yanı sıra, okul öncesi dönem çocuklarında beden algısına yönelik nitel araştırmalara da ihtiyaç duyulmaktadır. Özellikle okul öncesi dönemde beden algısını inceleyen araştırmaların yapılması, sonra ki gelişim aşamaları olarak, ön ergenlik ve ergenlik döneminde beden memnuniyetsizliğine bağlı problemlerin önlenmesi ve bu konuda erken müdahale programları oluşturulmasında fayda sağlayabilir. 


\title{
EXTENDED ABSTRACT
}

\section{Body Image in Preschool Period}

\author{
* \\ Mustafa Kale - Sara Hurşidi - Ayşe Balci Karaboğa \\ Çă̆ Üniversitesi, Mersin Üniversitesi
}

Body perception is a broad term that includes thoughts, feelings, perceptions and behaviors about one's body. Body perception is accepted as a multidimensional and subject to different disciplines due to its cognitive, emotional and physical effects on the person. Body perception includes the individual's positive or negative connection with his body, his bodily experiences, his feelings about his body, and his attitudes altogether. Research on body perception focuses on people's perceptions, feelings and attitudes about the shape, proportions, body size and appearance of their own body (Collins, 1991; Gragon, 2017).

The main reason for this focus is the effects of people's concerns about their bodies on their physical and mental health. It consists of two components: body perception, perception and attitude. In this classification, the perceptual component refers to the individual's predictions about his body size and shape, while the attitudinal component refers to the individual's attitudes and emotions towards his own body. While the perceptual component is considered as a judgment, the attitudinal component is generally associated with emotion and mental representations. In line with these two components, the individual has a satisfaction or dissatisfaction with his body. There is a general belief that concerns about body perception start when the body changes in adolescence. However, different studies reveal that primary school-age children have judgments of being thin and ideal, and even seven-year-old children report dissatisfaction with their bodies. In fact, current studies provide evidence that body dissatisfaction starts from a very early age and causes anxiety in individuals at other stages of the lifelong development process and negatively affects physical and psychological health. When the effective factors related to body perception of children in preschool period are examined, 
it is stated that models about the body are especially effective on parents, media, peer groups, even preschool teachers and educational materials (Neves, Cipriani, Meireles, Morgado, and Ferreira, 2017).

Studies on body dissatisfaction have shown that if body dissatisfaction seen in children from an early age is not intervened, especially in adolescence, low self-esteem and depressive symptoms, unsafe sexual behaviors, clinical eating disorders, overweight, anorexia, unhealthy diet or unhealthy muscle building reveals that their behaviors (Pope, Kanayama, and Hudson, 2012; Savaşhan Sarı, Aydoğa, and Erdal, 2015; Schebendach and Roth, 2019) show negative consequences including alcohol and cigarette addiction. Until recently, research investigating the long-term consequences of childhood body dissatisfaction is very limited.

In Turkey, the first study of body image related reached, Özbaydar (1967) 's written in the field of psychology, "Body Image Introversion and extroversion" seems to begin with the book. Later, when the theses on body perception were examined in Turkey, it was determined that the first graduate thesis was prepared in 1996. It is seen that 148 theses from different disciplines on "body perception" were produced between 1996 and 2020. However, when the process is examined, it is seen that there are a limited number of studies on body perception in Turkey and these studies have intensified especially between 2016-2020 (Higher Education Institution Thesis Center, 2020).

It is seen that the current studies focus on pre-adolescence, adolescence and adulthood in terms of sampling. On the other hand, studies on infancy and pre-school period are very limited. This limitation can be thought to be due to the fact that adaptation studies of body perception and measurement tools have not been carried out in Turkey yet. However, when the international literature is examined, qualitative, quantitative and mixed methods are used in studies examining body perception in childhood. In addition, it is seen that visual scales, which are used extensively in childhood body perception studies, are used by stimulating different cultures.

In the research conducted in turkey, gender as intense body image, as well as demographic variables such as age and illness, anxiety, self-perception, levels of assertiveness is seen as opposed to factors such as diet and exercise(Ata Vural, Sharp, 2014, Aries and fear Owen, 2019; Kurban, 2019). It is seen that the existing studies mostly work with women, and the studies on 
body perception in men are very limited. These studies were examined in health sub-fields such as psychology, psychiatry, medicine, nutrition and dietitian, and nursing with a positi-vist approach (Haspolat, 2019; Helvall, 2019; İncedal, 2016).

In conclusion, considering that the development of body perception takes place under the influence of many factors (Gragon, 2017), studies in different disciplines and even different disciplines examine body perception together are needed in Turkey. Similarly, in Turkey, there is a need for scale development and adaptation studies, especially for the body perception of infancy and preschool children.

In this context, besides culture-sensitive measurement tools, qualitative studies on body perception in pre-school children are also needed. Conducting studies that examine body perception especially in the pre-school period may be beneficial in preventing problems related to body dissatisfaction during pre-adolescence and adolescence and establishing early intervention programs in this regard.

\section{Kaynakça / References}

Anschutz, D., Engels, R., Van Leeuwe, J., ve van Strien, T. (2009). Watching your weight? The relations between watching soaps and music television and body dissatisfaction and restrained eating in young girls. Psychology and Health, 24, 1035-1050.

Birbeck, D., ve Drummond, M. (2005). Interviewing, and listening to the voices of, veryyoung children on body image and perceptions of self. Early Child Development and Care, 175(6), 579-596. http://dx.doi.org/10.1080/03004430500131379.

Brown, A. T., Cash, T. F., ve Mikulka, P. J. (1990) Attitudinal body-ımage assessment: factor analysis of the body-self relations questionnaire, Journal of Personality Assessment, 55(1-2), 135-144.

Brownell, K. D., ve Napolitano, M. A. (1995). Distorting reality for children: Body size proportions of Barbie and Ken dolls. International Journal of Eating Disorders, 18(3), 295-298. doi:10.1002/1098-108x(199511)18:3<295::aideat2260180313>3.0.co;2-r

Cash, T. F. (2002). Cognitive behavioral perspectives on body image. T. F. Cash \& T. Pruzinsky (Ed.), Body image: A handbook of theory, research, and clinical practice içinde (s. 38-46). New York: Guilford Press.

Cash, T. F. (2004). Body image: Past, present, and future. Body Image, 1(1), 15. doi:10.1016/s1740-1445(03)00011-1. 
Clark, L. A., ve Tiggemann, M. (2006). Appearance culture in nine- to 12-year-old girls: Media and peer influences on body dissatisfaction. Social Development, 15(4), 628-643. http://dx.doi.org/10.1111/j.1467-9507.2006.00361.x.

Clark, L. A., ve Tiggemann, M. (2008). Sociocultural and individual psychological predictors of body image in young girls: A prospective study. Developmental Psychology, 44(4), 1124.

Cook, S. J., MacPherson, K., ve Langille, D. B. (2007). Far from ideal: Weight perception, weight control, and associated risky behaviour of adolescent girls in Nova Scotia. Canadian Family Physician, 53, 678-684.

Costa, L., Silva, D. A., Almeida, S., ve de Vasconcelos, F. (2015). Association between inaccurate estimation of body size and obesity in schoolchildren. Trends in Psychiatry And Psychotherapy, 37(4), 220-226. https://doi.org/10.1590/2237-60892015-0009.

Damiano, S. R., Paxton, S. J., Wertheim, E. H., McLean, S. A., ve Gregg, K. J. (2015). Dietary restraint of 5-year-old girls: Associations with internalization of the thin ideal and maternal, media, and peer influences. International Journal of Eating Disorders, 48, 1166-1169. http://dx.doi.org/10.1002/eat.22432.

Davison, K. K., ve Birch, L. L. (2001). Weight status, parent reaction, and self-concept in five year-old girls. Pediatrics, 107(1), 46-53. http://dx.doi.org/10.1542/peds.107.1.46.

Davison, K. K., Markey, C. N., ve Birch, L. L. (2003). A longitudinal examination of patterns in girls' weight concerns and body dissatisfaction from 5 to 9 years. International Journal of Eating Disorders, 33, 320-332.

Dittmar, H., Halliwell, E., ve Ive, S. (2006). Does Barbie make girls want to be thin? The effect of experimental exposure to images of dolls on the body image of 5- to 8-year-old girls. Developmental Psychology, 42, 283-292.

Dohnt, H. K., ve Tiggemann, M. (2006a). Body image concerns in young girls: The role of peers and media prior to adolescence. Journal of Youth and Adolescence, 35, 141-151.

Dohnt, H. K, ve Tiggemann, M. (2006b). The contribution of peer and media influences to the development of body satisfaction and self-esteem in young girls: A prospective study. Developmental Psychology, 42, 929-936.

Dohnt, H. K., ve Tiggemann, M. (2008). Promoting positive body image in young girls: An evaluation of 'Shapesville'. European Eating Disorders Review, 16, 222-233.

Drummond, M. (2012). Boy's bodies in early childhood. Australasian Journal of Early Childhood, 37, 107-114. 
Eisenberg, M. E., Neumark-Sztainer, D., ve Story, M. (2003). Association of weight-based teasing and emotional well-being among adolescents. Archives of Pediatrics and Adolescent Medicine, 157, 733-738.

Elenbaas, L., Rizzo, M. T., Cooley, S., ve Killen, M. (2016). Rectifying social inequalities in a resource allocation task. Cognition, 155, 176-187. https://doi.org/10.1016/.j.cognition.2016.07.002

Gleeson, K., ve Frith, H. (2006). (De)constructing body image. Journal of health psychology, 11(1), 79-90. https://doi.org/10.1177/1359105306058851.

Goldschmidt, A. B., Wall, M., Choo, T.-H. J., Becker, C., ve Neumark-Sztainer, D. (2016). Shared risk factors for mood-, eating-, and weight-related health outcomes. Health Psychology, 35, 245-252. http://dx.doi.org/10.1037/hea0000283.

Grogan, S. (2017). Body image: Understanding body dissatisfaction in men, women and children. USA: Routledge.

Harrison, K., ve Hefner, V. (2006). Media exposure, current and futurebody ideals, and disordered eating among preadolescent girls: a longitudinal panel study. Journal of Youth and Adolescence, 35(2), 146-156. doi:10.1007/s10964-005-9008-3.

Hart, L. M., Damiano, S. R., ve Paxton, S. J. (2016). Confident body, confident child: A randomized controlled trial evaluation of a parenting resource for promoting healthy body image and eating patterns in 2- to 6-year old children. The International Journal of Eating Disorders, 49(5), 458-472. http://dx.doi.org/10.1002/eat.22494.

Hayes, S., ve Tantleff-Dunn, S. (2010). Am I too fat to be a princess? Examining the effects of popular children's media on young girls' body image. British Journal of Developmental Psychology, 28, 413-426. http://dx.doi.org/10.1348/ $026151009 X 424240$.

Hendriks, A. (2002). Examining the effects of hegemonic depictions of female bodies on television: A call for theory and programmatic research. Critical Studies in Media Communication, 19(1), 106.

Hendriks, A., ve Burgoon, M. (2003).The relationship between fashion magazine consumption and body satisfaction in women: Who is most at risk of influence? Paper presented at the meeting of the International Communication Association, San Diego, CA.

Holub, S. C., Tan, C. C., ve Patel, S. L. (2011). Factors associated with mothers' obesity stigma and young children's weight stereotypes. Journal of Applied Developmental Psychology, 32, 118-126.

Jellinek, R. D., Myers, T. A., ve Keller, K. L. (2016). The impact of doll style of dress and familiarity on body dissatisfaction in 6- to 8-year-old girls. Body Image, 18, 7885. http://dx.doi.org/10.1016/j.bodyim.2016.05.003 
Jendrzyca, A., ve Warschburger, P. (2016). Weight stigma and eating behaviors in elementary school children: A prospective population-based study. Appetite, 102, 51-59. http://dx.doi.org/10.1016/j.appet.2016.02.005

Koç, M. S., ve KorkutOwen, F. (2019). Relationships between self-compassion and body image satisfaction, body-mass index, age and parental attitudes. Hacettepe University Journal of Education. doi: 10.16986/HUJE.2019053979

Haspolat, N.K. (2016). Üniversite öğrencilerinde beden imajı benlik saygısı ve sosyal fobinin incelenmesi. Yayımlanmamış yüksek lisans tezi, Erzincan Üniversitesi, Erzincan.

Kurban, M. (2019). Üniversite öğrencilerinin beden algılar, yeme tutumlar ve beden kitle indeksi durumlan arasındaki ilişkinin incelenmesi. Yayımlanmamış yüksek lisans tezi, İstanbul Üniversitesi, İstanbul.

Helval, E.E. (2019). Erken dönem uyumsuz şemalar ile yeme tutumu arasındaki ilişkide yakın ilişkilerin, vücut algısının ve benlik saygısının aracı rolü. Yayımlanmamış yüksek lisans tezi, Başkent Üniversitesi, Ankara.

İncedal, S. (2016). Karaman il merkezi lise öğrencilerinin beden algıst ve yeme tutumlarnnın değerlendirilmesi. Yayımlanmamış yüksek lisans tezi, Yeditepe Üniversitesi, İstanbul.

Latner, J. D., ve Schwartz, M. B. (2005). Weight bias in a child's world. K. D. Brownell, R. M. Puhl, M. B. Schwartz, ve L. Rudd (Eds.), Weight bias: Nature, consequences and remedies içinde (s. 54-67). New York: The Guilford Press.

Latner, J. D., Durso, L. E., ve Mond, J. M. (2013). Health and health-related quality of life among treatment seeking overweight and obese adults: Associations with internalized weight bias. Journal of Eating Disorders, 1, 3.

Levine, M. P., ve Piran, N. (2004). The role of body image in the prevention of eating disorders. Body Image, 1(1), 57-70. doi:10.1016/s1740-1445(03)00006-8.

Lewis, M., ve Brooks-Gunn, J. (1979). Social cognition and the acquisition of self. New York, NY: Plenum Press.

Lowes, J., ve Tiggemann, M. (2003). Body dissatisfaction, dieting awareness and the impact of parental influence in young children. British Journal of Health Psychology, 8, 135-147.http://dx.doi.org/10.1348/135910703321649123.

McCabe M.P., Ricciardelli L.A., Stanford J., Holt K., Keegan S. ve Miller L. (2007) Where is all the pressure coming from? Messages from mothers and teachers about preschool children's appearance, diet and exercise. European Eating Disorders Review 15, 221-230.

McNinch, H. (2013). Fat bullying of girls in school: Implications for pre-service teacher education. MEd Thesis, Faculty of Education, Lakehead University. 
Mendelson, B. K., ve White, D. (1982). Relation between body esteem and self-esteem of obese and normal children. Perceptual and Motor Skills, 54, 899-905.

Musher-Eizenman, D. R., Holub, S. C., Edwards-Leeper, L. A., Persson, A. V., ve Goldstein, S. E. (2003). The narrow range of acceptable body types of preschoolers and their mothers. Journal of Applied Developmental Psychology, 24, 259-272. http://dx. doi.org/10.1016/S0193-3973(03)00047-9.

Neves, C. M., Cipriani, F. M., Meireles, J., Morgado, F., ve Ferreira, M. (2017). Body Image In Childhood: An Integratıve Literature Review. Imagem Corporal Na Infâncıa: Uma Revıão Integratıva Da Literatura. Revista paulista de pediatria : orgao oficial da Sociedade de Pediatria de Sao Paulo,35(3), 331-339. https://doi.org/10.1590/1984-0462/;2017;35;3;00002

Özbaydar, B. (1967). Vücut İmajı ve İçedönüklük - Dışadönüklük. İ.Ü. Edebiyat Fakültesi Yayınları. İstanbul.

Paraskeva, N., ve Diedrichs, P. C. (2020). Body Image, Esteem, and Dissatisfaction during Childhood. The Encyclopedia of Child and Adolescent Development, 112. doi:10.1002/9781119171492.wecad192

Paxton S. J., ve Damiano S. R. (2017). The development of body image and weight bias in childhood. Adv Child Development Behaviour;52:269-298.

Piran, N. (2016). Embodied possibilities and disruptions: The emergence of the experience of embodiment construct from qualitative studies with girls and women. Body Image, 18, 43-60.

Pope, H.G., Jr., Kanayama, G., ve Hudson, J. I. (2012). Risk factors for illicit anabolicandrogenic steroid use in male weightlifters: A cross-sectional cohort study. Biological Psychiatry, 71, 254-261. http://dx.doi.org/10.1016/j.biopsych.2011.06.024.

Puhl, R. M., veHeuer, C. A. (2009). The stigma of obesity: A review and update. Obesity, 17, 941-964.

Puhl, R., ve Suh, Y. (2015). Health consequences of weight stigma: Implications of obesity prevention and treatment. Current Obesity Reports, 4, 182-190.

Ricciardelli, L. A., ve McCabe, M. P. (2001). Children's body image concerns and eating disturbance: A review of the literature. Clinical Psychology Review, 21, 325-344.

Rice, K., Prichard, I., Tiggemann, M., ve Slater, A. (2016). Exposure to Barbie: Effects on thin-ideal internalisation, body esteem and body dissatisfaction among young girls. Body Image, 19, 142-149.

Roosen, K. M., ve Mills, J .S. (2014). Body Image, Overview. Teo T. (eds) Encyclopedia of Critical Psychology. Springer, New York, NY. https://doi.org/10.1007/978-14614-5583-7 403. 
Savaşhan Ç, Sarı, O., Aydoğan, Ü., ve Erdal, M. (2015). İkokul çağındaki çocuklarda obezite görülme sıklı̆̆ı ve risk faktörleri. Türk Aile Hekimi Dergisi; 19 (1): 14-2.

Schilder, P. (1935/1950). The image and appearance of the human body. New York: International Universities Press.

Schooler, D. (2013). Early adolescent body image predicts subsequent condom use behavior among girls. Sexuality Research and Social Policy, 10,52-61. http://dx.doi.org/10.1007/s13178-012-0099-9.

Sherman, A., ve Zurbriggen, E. (2014). Boys can be anything: Effect of Barbie play on girls' career cognitions. Sex Roles, 70, 195-208. doi:10.1007/s11199-014-0347-y.

Slade, P. D., Dewey, M. E., Newton, T., Brodie, D., ve Kiemle, G. (1990). Development and preliminary validation of the body satisfaction scale (BSS). Psychology $\mathcal{E}$ Health, 4, 213-220. http://dx.doi.org/10.1080/08870449008400391.

Smolak, L. (2011). Body image development in childhood. T. Cash ve L. Smolak (Eds.), Body Image: A handbook of science, practice and prevention içinde (2. bsm., s. 67-75). New York. Guilford Press.

Spiel, E. C., Paxton, S. J., ve Yager, Z. (2012). Weight attitudes in 3- to 5-year-old children: Age differences and cross-sectional predictors. Body Image, 9(4), 524-527. http://dx.doi.org/10.1016/j.bodyim.2012.07.006.

Spiel, E., Rodgers, R. F., Paxton, S. J., Wertheim, E. H., Damiano, S. D., Gregg, K. J., ve McLean, S. A. (2016). "He's got his father's bias": Parental influence on weight bias in young children. British Journal of Developmental Psychology, 34, 198-211, http://dx.doi.org/10.1111/bjdp.12123.

Strauss, R. S., ve Pollack, H. A. (2003). Social marginalization of overweight children. Archives of Pediatrics and Adolescent Medicine, 157, 746-752.

Sundgot-Borgen, C., Stenling, A., Rosenvinge, J. H., Pettersen, G., Friborg, O., SundgotBorgen, J., ... , Bratland-Sanda, S. (2020). The Norwegian healthy body image intervention promotes positive embodiment through improved self-esteem. Body Image, 35, 84-95. doi:10.1016/j.bodyim.2020.08.014.

Striegel-Moore, R. H., ve Kearney-Cooke, A. (1994). Exploring parents' attitudes and behaviors about their children's physical appearance. International Journal of Eating Disorders, 15(4), 377-385. https://doi.org/10.1002/eat.2260150408

Tatangelo, G. L., ve Ricciardelli, L. A. (2015). Children's body image and social comparisons with peers and the media. Journal of Health Psychology, 22(6), 776787. doi:10.1177/1359105315615409 
Tatangelo, G. L., McCabe, M., Mellor, D., ve Mealey, A. (2016). A systematic review of body dissatisfaction and sociocultural messages related to the body among preschool children. Body Image, 18, 86-95. http://dx.doi.org/10.1016/j.bodyim. $\underline{2016.06 .003}$

Thompson, J. K., Heinberg, L. J., Altabe, M., ve Tantleff Dunn, S. (1999). Exacting beauty: Theory, assessment, and treatment of body image disturbance. Washington, DC: American Psychological Association.

Tiggemann, M., ve Pennington, B. (1990). The development of gender differences in body-size dissatisfaction. Australian Psychologist, 25, 306-313. http://dx.doi.org/ 10.1080/00050069008260025.

Tremblay, L., Lovsin, T., Zecevic, C., ve Larivière, M. (2011). Perceptions of self in 3-5years old children: a preliminary investigation into the early emergence of body dissatisfaction. Body image, 8(3), 287-292. https://doi.org/10.1016/j.bodyim.2011.04.004

Truby, H., vePaxton, S. J. (2002). Development of the children's body image scale. British Journal of Clinical Psychology, 41, 185-203. http://dx.doi.org/10.1348/014466502163967.

Truby, H., ve Paxton, S. J. (2008). The children's body image scale: Reliability and use with international standards for body mass index. British Journal of Clinical Psychology, 47, 119-124. http://dx.doi.org/10.1348/014466507X251261.

Tzampazi, F., Kyridis, A., ve Christodoulou, A. (2013). What will I be when I grow up? Children's preferred future occupations and their stereotypical views. International Journal of Social Science Research, 1(1), 19-38.

Van Vonderen K, ve Kinnally W. (2012). Media effects on body image: Examining media exposure in the broader context of internal and other social factors. American Communication Journal. 14(2), 41-57.

Wong, Y., Chang, Y. J., ve Lin, C. J. (2013). The influence of primary caregivers on body size and self-body image of preschool children in Taiwan. Asia Pacific journal of clinical nutrition, 22(2), 283-291.https://doi.org/10.6133/apjon.2013.22.2.05

Yüksekögrretim Kurulu Tez Merkezi. (2020). Anasayfa. https://tez.yok.gov.tr/ adresinden 20.11.2020 tarihinden erişildi. 


\section{Kaynakça Bilgisi / Citation Information}

Kale, M., Hurşidi, S. ve Karaboğa, A. B. (2021). Okul öncesi dönemde beden algısı. OPUS-Uluslararası Toplum Araştırmaları Dergisi, 17(34), 1408-1435. DOI: 10.26466/opus.829749 